\title{
Clinical Equivalence of Generic Clozapine
}

\author{
Daniel J. Healy, M.D. \\ Stephan Taylor, M.D. \\ Mona Goldman, Ph.D. \\ Kris Barry, Ph.D. \\ Frederic Blow, Ph.D. \\ Karen K. Milner, M.D.
}

\begin{abstract}
Objective: To determine if mental health service utilization increases when patients are converted to generic clozapine. Method: About 125 patients taking clozapine in a community mental health clinic were switched from Novartis Clozaril to generic clozapine (Mylan Pharmaceuticals). Serum clozapine levels were obtained 2 weeks before, and 2 weeks after, the switch to generic clozapine. The number of outpatient visits, emergency room visits, and hospitalizations in the year prior to the switch were compared to those in the year following the switch, to determine service utilization. Results: Psychiatric emergency room visits decreased, but clozapine serum levels, inpatient hospital days, partial hospital admissions, and outpatient psychiatrist visits did not change after the switch to generic clozapine. Conclusions: There were no significant increases in mental health service utilization after the conversion to Mylan generic clozapine. The switch to Mylan generic clozapine was cost effective, as the reduction in pharmacy costs was not offset by increased utilization costs.
\end{abstract}

KEY WORDS: antipsychotics; community mental health center; schizophrenia.

Daniel J. Healy (Clinical Assistant Professor), Stephan Taylor (Associate Professor), Mona Goldman (Research Investigator), Kris Barry (Research Associate Professor), Frederic Blow (Associate Professor \& Research Associate Professor), and Karen K. Milner (Clinical Assistant Professor) are affiliated with the Department of Psychiatry, University of Michigan Health System.

Address correspondence to Karen K. Milner, M.D., Department of Psychiatry, University of Michigan Health System, 1500 E. Medical Center Drive, Ann Arbor, MI 48109-0020, USA; e-mail: kmilner@umich.edu. 


\section{INTRODUCTION}

Clozapine is the preferred antipsychotic treatment for patients with treatment refractory schizophrenia (Expert Consensus Guidelines, 2003) but the high cost of this therapy has made the use of generic formulations of the drug very appealing. However, several recent reports have suggested that patients switched to generic clozapine may experience symptom exacerbation or lower serum levels on a generic formulation (Kluznik, Walbek, Farnsworth, Melstrom, 2001; Mofsen \& Balter, 2001). This is undesirable from a clinical standpoint, as well as from a budgetary standpoint; more money may be spent on clinical delivery services than is saved from the cost of the medication. Therefore, we examined mental health services utilization in patients during the year before and the year after a switch from Novartis Clozaril to Mylan generic clozapine to determine if service utilization increases with the use of generic clozapine.

\section{METHOD}

Patients 18 years of age and older, in a Clozapine Clinic in a community mental health setting were all switched from brand-name clozapine (Clozaril[registered], Novartis) to generic clozapine (Mylan Pharmaceuticals) in January, 2001. This decision was made by Washtenaw County Community Mental Health (CMH) and the University of Michigan Pharmacy Service to reduce pharmacy costs, and Mylan was selected based on Mylan Pharmaceuticals' data on the comparable bioavailability of this preparation. Patients had blood drawn for clozapine levels 2 weeks before, and 2 weeks after, the switch to generic clozapine, as part of the quality assurance measurements taken by Washtenaw County CMH. These levels were drawn at the same time as the routine white blood count levels were drawn, so there was no coordination performed to assess peak or trough levels in these patients.

The University of Michigan Institutional Review Board and the Washtenaw County Community Mental Health Review Panel both approved the retrospective examination of patient records for a comparison of service utilization 1 year before and 1 year after the switch to generic clozapine. Since the decision to switch patients to generic clozapine was not part of a research project, and the retrospective analysis of these data would not identify the patients, informed consent was not required for this study. Information about outpatient psychiatrist visits, psychiatric emergency room visits, inpatient hospitalizations, crisis center utilization, clozapine dose (at switch and 1 year later), and adjunct antipsychotics were collected from the medical record. Plasma clozapine levels were compared using paired $t$-tests. Wilcoxon Signed Ranks tests were used to compare inpatient hospital days, partial hospital admissions, psychiatric emergency room visits, and outpatient psychiatrist visits in the year before, and the year after, the switch to generic clozapine. 


\section{RESULTS}

One hundred and eight patients were on clozapine during the 2 year period, and were included in the study. There were 62 men and 46 women, and the average age of the patients was 42.5 years. Ninety two patients were white, two were Hispanic, and there were 14 African Americans. No patient had to be withdrawn from generic clozapine secondary to leucopenia or agranulocytosis. The average daily clozapine dose was $452 \pm 177$ in December of 2000 and $452 \pm 176$ in December of 2001 ( $\mathrm{df}=106, t=0.42, p=0.97$ ). Sixteen patients required an increase in their clozapine dose, 11 required a decrease in dose, and 75 patients were on the same dose at the conclusion of 2001. Nine patients required the addition of another antipsychotic, three patients had a change of their adjunct antipsychotic, and six patients were able to reduce the dose of their adjunct antipsychotic. Eighty six patients had their plasma drawn 2 weeks before and after the switch to generic clozapine, and there was no significant difference in plasma levels (df $1,171, F=2.93, p=$ N.S.) (Table 1 ). There were no significant differences for inpatient hospital days (239 hospital days with Novartis Clozaril, 101 hospital days with Mylan clozapine $n=106, p=0.37$ ), crisis center admissions (24 admission with Novartis Clozaril, 17 admissions with Mylan clozapine, $n=106, p=0.40$ ), or outpatient psychiatrist visits (590 visits with Novartis Clozaril, 567 visits with Mylan clozapine $n=106, p=0.84$ ) (Table 1 ). There was a significant decrease in psychiatric emergency room visits (69 visits with Novartis Clozaril, 32 visits with Mylan clozapine, $n=106, p=0.04$ ) (Table 1).

\section{DISCUSSION}

These data demonstrate that there was no increase in service utilization by patients who were converted to generic clozapine. In fact, all of our measures of utilization decreased, although this decrease was significant only for emergency room visits. Therefore, it is extremely unlikely that our design merely failed to detect a small increase in utilization. The lack of an increase in utilization is consistent with previous reports by Makela et al. (2003) and Stoner et al. (2003) demonstrating that patients switched to generic clozapine did not show a deterioration in clinical status 2-4 months after the switch. Further, Sajbel, Carter, and Wiley (2001) showed a lack of leucopenia or a need to change clozapine dosages when patients were switched to Zenith 
TABLE 1

Service utilization and medication levels before and after switching from brand-name (Novartis) to generic (Mylan) clozapine

\begin{tabular}{|c|c|c|c|c|}
\hline & $n$ & Novartis & Mylan & $p$-value ${ }^{1}$ \\
\hline \multicolumn{5}{|l|}{ Service Utilization $^{2}$} \\
\hline Inpatient hospital days & 106 & 239 & 101 & .37 \\
\hline Crises center admissions & 106 & 24 & 17 & .40 \\
\hline $\begin{array}{l}\text { Outpatient physician } \\
\text { visits }\end{array}$ & 106 & 590 & 567 & .84 \\
\hline $\begin{array}{l}\text { Psychiatric emergency } \\
\text { room visits }\end{array}$ & 106 & 69 & 32 & .04 \\
\hline \multicolumn{5}{|l|}{ Medication } \\
\hline $\begin{array}{l}\text { Dose (mean daily } \\
\pm \mathrm{SD} ; \mathrm{mg} / \text { day })^{3}\end{array}$ & 106 & $452 \pm 177$ & $452 \pm 176$ & .97 \\
\hline $\begin{array}{l}\text { Plasma clozapine level } \\
(\text { mean } \pm \mathrm{SD} ; \mathrm{ng} / \mathrm{ml})^{4}\end{array}$ & 86 & $599 \pm 319$ & $691 \pm 383$ & .09 \\
\hline \multicolumn{5}{|c|}{$\begin{array}{l}{ }^{1} \text { Wilcoxon Signed Ranks test used in analyses of service utilization and } t \text {-tests used for medication } \\
\text { data. } \\
\text { 2 Service utilization was measured from January } 1 \text {-December } 31,2000 \text { for Novartis and from } \\
\text { January 1-December } 31,2001 \text { for Mylan. } \\
{ }^{3} \text { Medication dose was ascertained just before the switch to generic clozapine and } 1 \text { year after. } \\
{ }^{4} \text { Plasma levels were measured } 2 \text { weeks before the switch to generic clozapine and } 2 \text { weeks after. }\end{array}$} \\
\hline
\end{tabular}

Goldline Pharmaceuticals clozapine, which is also consistent with our data. Although some reports have suggested that some patients have symptom exacerbation after switching to generic clozapine (Kluznik et al., 2001; Mofsen \& Balter, 2001), our proxy measures of utilization did not reflect increasing symptoms. However, because we did not assess clinical status before and after the switch, it is possible that patients did exhibit symptom change with the switch.

Similarly, the lack of a change in utilization may reflect the gradual stabilization of these patients over time, or the gradual reduction of patients using inpatient or psychiatric emergency room services in general (which is a goal in the treatment of the seriously and persistently mentally ill). Our data do not address these points directly. Still, these points do not detract from our conclusion that the switch to Mylan generic clozapine did not lead to a service utilization increase immediately after the switch. 
Several studies have emphasized the importance of bioavailability and medication tolerability when prescribing generic clozapine. Lam, Ereshefsky, Toney, and Gonzales, (2001) found that 5 of 21 patients had area under the concentration-time curve levels below the 80-120\% range when taking Zenith Goldline Pharmaceuticals generic clozapine, suggesting a difference in bioavailability. Further, Cutler (2001) showed that 6 of 30 patients had orthostatic hypotension when taking Creighton generic clozapine. None of our patients had to stop generic clozapine because of hypotension, but there was a statistically nonsignificant increase in average clozapine plasma levels with Mylan generic clozapine. Therefore, clinicians may want monitor plasma clozapine levels if the emergence of dose-dependent side effects occurs.

Finally, Tse, Thompson, and Procyshyn (2003) emphasized that any cost savings realized in converting to a less expensive formulation of an antipsychotic cannot be lost by an increase in service utilization. We did not find any increase in service utilization in this study, so pharmacy savings do not appear to be lost due to compensatory increases in service utilization.

In conclusion, there were no significant increases in mental health service utilization after the conversion to Mylan generic clozapine. The switch to Mylan generic clozapine was cost effective, as the reduction in pharmacy costs was not offset by increased utilization costs.

\section{ACKNOWLEDGMENTS}

This study was supported by the Department of Psychiatry, University of Michigan Health Systems and by the Washtenaw County Community Mental Health Administration. The authors wish to thank Robert Johnson for assistance with data acquisition.

\section{REFERENCES}

Cutler, N. R. (2001). Pharmacokinetic studies of antipsychotics in healthy volunteers versus patients. Journal of Clinical Psychiatry, 62(Suppl 5), 10-13.

Expert Consensus Guideline Series (2003). Optimizing pharmacologic treatment of psychotic disorders. Journal of Clinical Psychiatry, 64(Suppl 12), 1-100.

Kluznik, J. C., Walbek, N. H., Farnsworth, M. G., \& Melstrom, K. (2001). Clinical effects of a randomized switch of patients from clozaril to generic clozapine. Journal of Clinical Psychiatry, 62(Suppl 5), 14-17. 
Lam, Y. W., Ereshefsky, L., Toney, G. B., \& Gonzales, C. (2001). Branded versus generic clozapine: bioavailability comparison and interchangeability issues. Journal of Clinical Psychiatry, 62(Suppl 5), 18-22.

Makela, E. H., Cutlip, W. D., Stevenson, J. M., Weimer, J. M., Abdallah, E. S., Akhtar, R. S., Aboraya, A. S., \& Gunel, E. (2003). Branded versus generic clozapine for treatment of schizophrenia. Annals of Pharmacotherapy, 37, 350-353.

Mofsen, R., \& Balter, J. (2001). Case reports of the reemergence of psychotic symptoms after conversion from brand-name clozapine to a generic formulation. Clinical Therapeutics, 23 , 1720-1731.

Sajbel, T. A., Carter, G. W., \& Wiley, R. B. (2001). Converting patients from brand-name clozapine to generic clozapine. Annals of Pharmacotherapy, 35, 281-284.

Stoner, S. C., Lea, J. W., Dubisar, B., Marken, P. A., Ramlatchman, L. V., \& Reynolds, J. (2003). A program to convert patients from trade-name to generic clozapine. Pharmacotherapy, 23, 806-810.

Tse, G., Thompson, D., \& Procyshyn, R. M. (2003). Generic clozapine: a cost-saving alternative to brand name clozapine? Pharmacoeconomics, 21, 1-11. 